\title{
Erratum To: Effect of Heat Treatment on the Magnetic Properties of a CuMn Alloy
}

\author{
Sultan Cansel Cucu ${ }^{1} \cdot$ Emine Aldırmaz $^{2}$
}

Published online: 3 May 2017

(C) Springer Science+Business Media New York 2017

Erratum to: J Supercond Nov Magn (2017) 30:197-201

DOI 10.1007/s10948-016-3699-4

The authors woud like to indicate the below corrections to the above referenced article.

In Figs. 3 and 4, the $y$-axis label Moment (emu/g) should be $\mathrm{M}(\mathrm{emu} / \mathrm{g})$.

The authors regret the oversight.

The online version of the original article can be found at http://dx.doi.org/10.1007/s10948-016-3699-4.

\footnotetext{
Emine Aldırmaz

ealdirmaz@gmail.com

1 Institute of Sciences, Amasya University, Amasya, Turkey

2 Department of Physics, Science and Arts Faculty, Amasya University, Amasya, Turkey
} 